\title{
Chartres, ZAC du bas bourg Saint-Brice
}

$n^{\circ} 4561$

Hervé Selles

\section{(2) OpenEdition}

Journals

Édition électronique

URL : http://journals.openedition.org/adlfi/13973

ISSN : 2114-0502

Éditeur

Ministère de la culture

Référence électronique

Hervé Selles, «Chartres, ZAC du bas bourg Saint-Brice », ADLFI. Archéologie de la France - Informations [En ligne], Centre, mis en ligne le 23 janvier 2015, consulté le 03 mai 2019. URL : http:// journals.openedition.org/adlfi/13973

Ce document a été généré automatiquement le 3 mai 2019.

(c) Ministère de la Culture et de la Communication, CNRS 


\title{
Chartres, ZAC du bas bourg Saint- Brice
}

$\mathrm{n}^{\circ} 4561$

\author{
Hervé Selles
}

Lien Atlas (MCC) :

http://atlas.patrimoines.culture.fr/atlas/trunk/index.php?

ap_theme=DOM_2.01.02\&ap_bbox=1.460;48.427;1.550;48.469

1 L'opération réalisée entre 1988 et 1999 est la troisième campagne d'évaluation du potentiel archéologique de la ZAC Saint-Brice de Chartres. Elle fait suite aux interventions de 1991 et 1995.

2 Elle confirme qu'à l'époque romaine, ce quartier péri-urbain est occupé par des monuments de dimensions exceptionnelles. Les aménagements antiques forment deux ensembles distincts (et d'orientation légèrement décalée), de chaque côté d'une voie de direction nord-sud. L'ouest des terrains est occupé par une construction monumentale qui a été reconnue sur plus de $100 \mathrm{~m}$ de longueur. Elle correspond à un portique doté d'absides et d'exèdres. Les murs du portique profondément fondés ont entre 1,60 m et $2 \mathrm{~m}$ de largeur. Ce portique s'étend vers le sud, sur une distance totale de plus de $300 \mathrm{~m}$. Il forme la façade d'un complexe monumental large de $200 \mathrm{~m}$. A ce jour, l'organisation interne du complexe est inconnue. On notera simplement que l'église de l'abbaye de Saint-Martin-en-Val (attestée à la période mérovingienne), est située exactement au centre de l'aménagement antique.

3 A l'est de la voie romaine, en direction de la rivière, se trouve un second ensemble monumental. Il rythme le front de rue de grands bâtiments en saillie par rapport à des constructions en retrait. La fonction de ce second ensemble est inconnue. Implantées sur la basse terrasse de la vallée de l'Eure, les constructions sont en partie immergées du fait de la remontée de la nappe phréatique. 
4 Malgré la proximité de l'ancienne abbaye de Saint-Martin-en-Val, aucune occupation médiévale organisée n'a été mise en évidence.

INDEX

Index géographique : Centre, Eure-et-Loir (28), Chartres Index chronologique : Gallo-romain

Mots-clés : monument, portique

operation Évaluation archéologique (EV) 